\title{
Heterogeneity in the Effect of Common Shocks on Health Care Expenditure Growth
}

\author{
Katharina Hauck ${ }^{a}$ and Xiaohui Zhang*b
}

May 2015

\footnotetext{
${ }^{a}$ School of Public Health, Imperial College London, UK

${ }^{\mathrm{b}}$ School of Management and Governance, Murdoch University, Perth, Australia

* corresponding author
}

\begin{abstract}
Health care expenditure growth is affected by important unobserved common shocks such as technological innovation, changes in sociological factors, shifts in preferences and the epidemiology of diseases. While common factors impact in principle all countries, their effect is likely to differ across countries. To allow for unobserved heterogeneity in the effects of common shocks, we estimate a panel data model of health care expenditure growth in 34 OECD countries over the years 1980 to 2012 where the usual fixed or random effects are replaced by a multifactor error structure. We address model uncertainty with Bayesian Model Averaging, to identify a small set of important expenditure drivers from 43 potential candidates. We establish 16 significant drivers of healthcare expenditure growth, including growth in GDP per capita and in insurance premiums, changes in financing arrangements and some institutional characteristics, expenditures on pharmaceuticals, population aging, costs of health administration, and inpatient care. Our approach allows us to derive estimates that are less subject to bias than in previous analyses, and provide robust evidence to policy makers on the drivers that were most strongly associated with the growth in health care expenditures over the past 32 years.
\end{abstract}

Key words: Health Care Expenditure Growth, Common Factor Models, Bayesian Model Averaging, Technological Change, Panel Data Analysis

Acknowledgements: We wish to thank Denzil Fiebig and the other participants of the Sixth Australasian Workshop on Econometrics and Health Economics, Melbourne, April 2015, for their helpful comments. We further thank Terkel Christiansen, Mickael Bech, Jørgen Lauridsen, Pascal Nielsen, Jochen Hartwig and JanEgbert Sturm for their support. 


\section{Introduction}

In empirical country-level models of health care expenditure (HCE) growth great importance is placed on common factors. These are exogenous influences on expenditure growth that are unobserved but affect all countries in specific time periods. The most prominent common factor is technological change, in particular advances in medical care technology. In addition, changes in sociological factors, lifestyle, epidemiology of diseases, shifts in preferences of patients, and the global economic situation are potentially important drivers of expenditure growth that are absorbed in the common factor if they are unobserved. Some studies have used proxies for technological change such as R\&D expenditures in all sectors or in health care (Okunade and Murthy, 2002), surgical procedures (Baker and Wheeler, 1998), the number of specific medical equipment (Weil, 1994), neonatal survival, or life expectancy and infant mortality (Dreger and Reimers, 2005). This is problematic because proxies are imperfect and results vary across studies. Therefore most studies still adopt variants of the 'residual approach' (Chernew and Newhouse, 2011, and references in table 1.3), which was pioneered for the economy in general by Solow (1957). It measures time-varying observable cost drivers, and generally attributes the rest of spending growth to technology and other common factors. They are captured by the residual for unobserved factors that are assumed to differ across countries, and by a time index (Gerdtham and Löthgren, 2000), timespecific intercepts (Di Matteo and Di Matteo, 1998) or year fixed effects (Smith et al., 2009) for factors that are assumed common.

Panel data models of HCE growth with year fixed effects rest on the assumption that the association between unobserved common factors and expenditure growth is homogenous. This implies that the impact of common shocks is assumed to be the same in all countries, and that there is no association between the residual, the unobserved common factors and observed determinants of expenditure growth. These assumptions have been challenged by research demonstrating that countries differ quite markedly in the rate by which they adopt technological innovations in health care, although knowledge innovations are in principle accessible to all, i.e. constitute common shocks (Greenhalgh et al., 2008). For example, in the adoption of innovation in cardiac procedures countries can be classified into three patterns: early start and fast adoption; late start/fast adoption; and late start/slow adoption (Lyttkens, 2001). While the literature on HCE growth is extensive, there has not been much progress with incorporating these findings. 
Our study allows for heterogeneity in the impact of common shocks, to identify the main drivers of HCE growth in OECD countries over the period 1980 and 2012. We estimate a panel data model of HCE growth where the usual fixed or random effects are replaced by a multifactor error structure as proposed by Pesaran (2006). The factor structure synthesizes the effects of shocks that may hit health spending in different time periods. While those common factors affect in principle all countries, our model allows for their differing impact on growth across countries. The theoretical literature has shown that a multifactor error structure leads to estimates that are less subject to bias. Main objective of our study is to generate unbiased estimates of the most important drivers of HCE growth. What constitutes 'most important' has been subject to some debate, because analysis of HCE growth is affected by high model uncertainty. While there is now an impressive amount of evidence on the individual importance of determinants (Chernew and Newhouse, 2011), there is little guidance for policy makers where to focus cost-containment efforts. We use Bayesian Model Averaging (BMA) to address model uncertainty in HCE growth analysis. It is a technique designed to help account for the uncertainty inherent in the model selection process, something which traditional econometric analysis often neglects. By averaging over many different competing models, BMA incorporates model uncertainty into conclusions about parameters and prediction. This technique allows us to identify a small set of highly influential expenditure drivers from many potential candidates. Our study offers two methodological contributions to the analysis of HCE growth, to derive results that are more accurate and informative than those from previous studies. We use common factor modelling to allow for heterogeneity in the impact of common shocks, and BMA to address model uncertainty. The improved results are then used to inform policy makers on the magnitude of impact of the most important drivers of HCE growth.

\section{Background}

Recently, the econometrics literature on panel data has focused on common factors that represent unobserved, time-varying heterogeneity that stems from omitted common variables or global shocks that affect each country or observational unit differently (Andrews, 2005, Pesaran, 2006, Bai, 2009, Peng and Forchini, 2014). Studies are mostly motivated by modelling of economic growth. It is assumed that common shocks affect output directly (through the total factor productivity or Solow residual), but also indirectly via the input in the production process (e.g. through investment decisions). When common shocks have 
homogeneous effects on the output, the model collapses to the usual time effect. It is the heterogeneity that gives rise to a factor structure. Earlier contributions to the literature allow only for models with factor structure in the errors (Case, 1991, Conley, 1999) for which consistent estimation of the parameters can be done by maximum likelihood procedures or by estimation procedures based on principal components applied to the residuals (Coakley et al., 2006). More recently, it has been noticed that common shocks are likely to affect both the dependent variable and the regressors and would thus induce endogeneity requiring more sophisticated estimation procedures (Andrews, 2005, Pesaran, 2006). Pesaran (2006) proposes estimators that are consistent when both the $\mathrm{N}$ and $\mathrm{T}$ dimensions tend to infinity. These results have been extended by Bai (2009) to set-ups that allow for a more complex dependence of the regressors on the unknown factors and factor loadings, by Su and Jin (2012) and Huang (2012) to semiparametric models, and by Peng and Forchini (2014) to models for fixed T and N tending to infinity and less restrictive conditions.

Common factor models have an obvious application in the analysis of HCE growth because of the importance of common shocks. If all heterogeneity in the effects of common shocks were observable, then the problem could be solved -or at least alleviated- by a specification that includes interactions terms between the observable regressors and time, and that allows for time-varying slope coefficients, as for example proposed by Chernew and Newhouse (2011). However, the literature finds that a substantial proportion of differences in the spread of technology, and other common shocks, is due to factors that are either unobservable altogether, or unobserved in the country level data that are typically used by studies on HCE growth (McClellan and Kessler, 1999, Lyttkens, 2001, Packer et al., 2006, Hashimoto et al., 2006, Greenhalgh et al., 2008). If this is the case, then changes in unmeasured factors may cause the observed relationship between covariates and spending to change over time. As a result, heterogeneity in the impact of latent common factors on HCE growth in countries introduces cross-section dependence, endogeneity and correlation between year fixed effects and regressors. This may lead to inconsistent estimates and erroneous inference on the importance of observable drivers of expenditure growth, a problem that cannot be eliminated with interaction terms and time-varying slopes. The factor structure can capture any contemporaneous correlation that arises from the common response of countries to such unanticipated events, and recognize that there is cross-country dependence in HCE, caused by unobservable common factors in specific time periods. 
We use the model proposed by Pesaran (2006), because we want to allow for the possibility that heterogeneity in the impact of common shocks on HCE growth could -at least partly- be explained by observable factors. These could relate to the organization of the health system, overall income level or other factors. For example, insurance tends to shield patients from most of the cost of care at the margin and passively reimburses on a disaggregated, feefor-service basis, which gives greater encouragement to quality and cost-increasing technology in insurance based systems; competition between providers fosters spread of quality improving and cost saving medical technology; higher incomes increase demand for quality and make innovations more profitable to introduce. It is even possible that certain health system traits do not have a great effect on spending growth in themselves, in particular if they change little over time; instead, their impact on spending growth predominantly arises because they are correlated with the common factor, and it is the interaction between the observed system trait and the unobserved common factor which impacts on spending.

Two studies have applied common factor modelling to the analysis of HCE. Baltagi and Moscone (2010) focus on the relation between HCE and GDP per capita, to address the long-standing issue of the magnitude of the income-elasticity of healthcare spending, using a panel of 20 OECD countries over the period 1971-2004. They control for both cross-section and spatial dependence. Heterogeneity is handled through fixed effects in a panel homogeneous model and through a panel heterogeneous model. Mello-Sampayo and SousaVale (2014) analyse the relationship between HCE and type of financing in a panel of 30 OECD countries from 1990 to 2009. Both studies focus on the time series properties of their model, and analyse absolute HCE (not growth) and only include a few regressors: population aged over 65 years old and under 15 years old, and proportion of government expenditure on total expenditure; Mello-Sampayo and Sousa-Vale (2014) also include two proxies of medical technology. Neither study estimates the magnitude of impact of cost drivers, the main objective of our study.

Identifying determinants of expenditure growth has proven difficult because of high model uncertainty. A large and varied number of potential determinants of expenditures have been suggested (Chernew and Newhouse, 2011), but for each study that finds evidence for a determinant, there is at least one other study that finds evidence against. Even if there is consensus, there is uncertainty about the magnitude of its impact. For example, nearly all studies uncover rising income -generally proxied by GDP per capita- as an important cost driver, but estimates of the income elasticity of HCEs vary (Hartwig, 2008). Model uncertainty 
forces researchers to ignore the uncertainty surrounding the model selection process and base inference on an essentially arbitrary chosen subset of regressors (Moral-Benito, 2010). We use Bayesian Model Averaging (BMA) on least squares estimation as proposed by Sala-i-Martin et al. (2004) extended to a panel data framework to estimate all model specifications given our data. We then examine whether the estimated results for any determinant are sufficiently stable ('robust') across most specifications. By doing so, we are considering not only the uncertainty associated with the parameter estimate conditional on a given model, but also the uncertainty of the parameter estimate across different models. This approach leads us to more reliable, or at least more honest, conclusions regarding the significance of the estimated effect of a determinant (Moral-Benito, 2010).

A recent paper by Hartwig and Sturm (2014) applies frequentist model averaging to the analysis of HCE growth for 33 OECD countries over the period 1970-2010. They test a large number of macroeconomic and institutional determinants of HCE growth. Results confirm earlier findings that GDP growth and a variable representing Baumol's 'cost disease' theory emerge as robust and statistically significant determinants of HCE growth. Depending on whether or not outliers are excluded, there are six additional robust drivers: the growth in expenditure on health administration, the change in the share of inpatient expenditure in total HCE, the (lagged) government share in GDP, the change in the insurance coverage ratio, the growth in land traffic fatalities and the growth in the population share undergoing renal dialysis.

\section{Data}

Main data source for our study is the OECD Health Statistics (OECD, 2014), supplemented with institutional variables of the organisational features of healthcare systems. These are binary variables, obtained from Christiansen et al. (2006) and extended to the year 2012 by us. In total, our study tests 43 determinants in 34 countries between 1980 and 2012. Table 1 lists countries, and table 2 presents variable descriptions and summary statistics. We broadly follow Hartwig and Sturm (2014) in choice of determinants, but we include additional variables that have been suggested in the literature. We follow common practice and convert all level variables into growth rates and all proportion/share variables into first differences.

The presence of missing values in the OECD data poses a problem. In order to expand the number of drivers that we can test for importance, and investigate changes in expenditures over a relatively long period from 1980 to 2012, we impute missing values for determinants 
with multiple imputation (MI) (STATA, 2013). We do not impute the dependent variable but drop country-years with missing values, thus creating an unbalanced panel (see table 1 for available country-years). We only analyse determinants if less than 50\% values are missing across country-years. MI predicts the missing data in a manner that allows for uncertainty about the values of the missing data, while at the same time maintaining the overall covariance structure of the variables. This ensures that causal inferences are not being driven by the randomness of a given imputation. MI adjusts the standard errors in the estimated relationship, to account for the fact that there is additional uncertainty relating to the imputation (Rubin, 1987).

MI proceeds in three steps (for details see section 4): (1) generate $M$ imputations (completed data sets); (2) conduct desired analysis on each imputation separately; (3) combine results obtained from the second step for each completed data set into a single multipleimputation result (Rubin, 1987, Kenward and Carpenter, 2007, Horton and Lipsitz, 2001). We use predictive mean matching using three nearest neighbours and $M=50$ imputed datasets, following White et al. (2011). This method fills in multiple variables iteratively using a sequence of univariate imputation methods with fully conditional specification of prediction equations. It accommodates arbitrary missing value patterns, and it allows us to include country and year dummies and utilise robust standard errors. Summary statistics for two imputed data sets and all imputed variables are presented in Table 3. Comparing the summary statistics of the imputed variables with the original ones in Table 2 , we are reasonably confident that the imputations can be used for further analysis.

\section{Econometric Framework}

The innovative contributions of our study are to account for heterogeneity in the effects of common factors by allowing a multifactor error structure, and to address model uncertainty with the use of Bayesian Model Averaging. These innovations allow us to derive unbiased estimates on the drivers that are most strongly associated with the growth in HCE. A panel data model of HCE growth with multifactor error structure (Pesaran, 2006, Bai, 2009) can be written as

$$
y_{i t}=\boldsymbol{x}_{i t}^{\prime} \boldsymbol{\beta}_{i}+\varepsilon_{i t}, \quad i=1, \ldots, N ; t=1, \ldots, T
$$


where $y_{i t}$ is HCE growth in country $i$ and time period $t ; \boldsymbol{x}_{i t}$ is a $k \times 1$ vector of regressors and $\boldsymbol{\beta}_{i}$ represents the heterogeneous coefficients for the $i$-th country. The error term is assumed to have a multiple factor structure

$$
\varepsilon_{i t}=\lambda_{i}^{\prime} f_{t}+e_{i t}
$$

where $\boldsymbol{f}_{t}=\left(f_{1 t}, \ldots, f_{m t}\right)^{\prime}$ is a $m \times 1$ ( $m$ is normally unknown) vector of unobserved factors, $\lambda_{i}=\left(\lambda_{1 i}, \ldots, \lambda_{m i}\right)^{\prime}$ is a $m \times 1$ vector of factor loadings and $e_{i t}$ is an idiosyncratic error with mean of zero and assumed to be uncorrelated with the regressors in $\boldsymbol{x}_{i t} \cdot{ }^{1}$ While a conventional panel data model allows for common shocks, it makes the restrictive assumption that they affect all countries in the same way. The factor structure represents a generalization of the conventional error components approach in the sense that it allows for unobserved timespecific factors to affect all countries in different ways; for example, it allows for variations in the rates by which countries adopt or implement new technology that becomes generally available in specific time periods.

Some of the causes of unobserved heterogeneity in the effects of common shocks remain unobserved, and would then be absorbed in the factor loadings. Therefore, in addition, we allow correlation of unobserved factors $f_{t}$ with observable cost drivers in $\boldsymbol{x}_{i t}$ and adopt the pooled common correlated effect (PCCE) estimator proposed by Pesaran (2006). The PCCE estimator does not require estimating $m$, the number of unobserved latent factors (except to assume $m$ is fixed and finite), and is valid when $\boldsymbol{f}_{t}$ are correlated with $\boldsymbol{x}_{i t}$. It is desirable to allow for such correlation, because some determinants that lead to heterogeneity in the impact of unobservable common shocks are observed in empirical models of HCE growth. For example, the spread of medical technological change has been shown to correlate with wellobservable drivers of costs such as income per capita and the extent of insurance coverage. Therefore unobserved shocks can be thought of as omitted variables. Failure taking them into account may lead to biased estimates of $\boldsymbol{\beta}$ 's .

\footnotetext{
${ }^{1}$ The conventional panel data model with standard two-way error components, i.e. $\varepsilon_{i t}=u_{i}+\eta_{t}+e_{i t}$ is a special case of (2) by setting $m=2, \lambda_{i}=\left(u_{i}, 1\right)^{\prime}$, and $f_{t}=\left(1, \eta_{t}\right)^{\prime}$ so that $\lambda_{i}^{\prime} f_{t}=u_{i}+\eta_{t}$, with $u_{i}$ representing an individual-specific time-invariant effect and $\eta_{t}$ a time-specific individual-invariant effect.
} 
Given the large number of potential growth determinants, there potentially exist an enormous amount of empirical models when the empirical researcher seeks to explore different combination of determinants. Suppose we have $K$ potential determinants, we then would have a maximum of $2^{K}$ possible combinations of regressors, i.e. $2^{K}$ models to estimate. Let $M_{r}$ $r=1,2, \ldots, 2^{K}$ ) denote the $r$-th model under consideration, then $M_{r}$ depends on a set of growth determinants, $\boldsymbol{X}^{r}$, and their corresponding coefficients $\beta^{r}$. Let $\boldsymbol{\beta}$ be a vector of parameters that has a common interpretation in all models, i.e. $\boldsymbol{\beta}$ is a function of $\boldsymbol{\beta}^{r}$ for each $r=1,2, \ldots, 2^{K}$ . For point estimations of $\boldsymbol{\beta}$, we can take expectations of the posterior densities of the parameters of all models under consideration, and obtain

$$
E(\boldsymbol{\beta} \mid \boldsymbol{y})=\sum_{r=1}^{2^{K}} p\left(M_{r} \mid \boldsymbol{y}\right) E\left(\boldsymbol{\beta} \mid \boldsymbol{y}, M_{r}\right)
$$

where the posterior probability of $M_{r}$, i.e. $p\left(M_{r} \mid \boldsymbol{y}\right)$, assesses the degree of support for model $M_{r}$, and $E\left(\boldsymbol{\beta} \mid \boldsymbol{y}, M_{r}\right)$ is the posterior expectation of $\boldsymbol{\beta}$ under model $M_{r}$. Following Leamer (1978), the posterior variance of $\boldsymbol{\beta}$ is given by

$$
\operatorname{Var}(\boldsymbol{\beta} \mid \boldsymbol{y})=\sum_{r=1}^{2^{K}} p\left(M_{r} \mid \boldsymbol{y}\right) \operatorname{Var}\left(\boldsymbol{\beta} \mid \boldsymbol{y}, M_{r}\right)+\sum_{r=1}^{2^{K}} p\left(M_{r} \mid \boldsymbol{y}\right)\left(E\left(\boldsymbol{\beta} \mid \boldsymbol{y}, M_{r}\right)-E(\boldsymbol{\beta} \mid \boldsymbol{y})\right)^{2}
$$

The posterior variance of $\boldsymbol{\beta}$ incorporates not only the weighted average of estimated variances from each individual model, but also the weighted variances in estimates of $\boldsymbol{\beta}$ across different models. Following Sala-i-Martin et al. (2004), we apply the so-called BACE (Bayesian Averaging of Classical Estimates) approach. In this approach, a diffuse prior is assumed for a given model $M_{r}$, therefore Bayesian posterior expectations of $\boldsymbol{\beta}$ are identical to the classical estimation from OLS. Then Equation (3) can be rewritten as

$$
E(\boldsymbol{\beta} \mid \boldsymbol{y})=\sum_{r=1}^{2^{K}} p\left(M_{r} \mid \boldsymbol{y}\right) \hat{\boldsymbol{\beta}}^{r}
$$

where $\hat{\boldsymbol{\beta}}^{r}$ is the generic OLS estimator for $\boldsymbol{\beta}$ from model $M_{r}$. By applying common factor model to our study, $\hat{\boldsymbol{\beta}}^{r}$ is the PCCE estimator. 
The logic of Bayesian inference is to obtain results for every possible model given the data, and average them. The weights in the averaging are the posterior model probabilities. The logic is straightforward, but implementation can be difficult when $2^{K}$ (the number of models under consideration) is large. It is then practically impossible to incorporate every possible model in the averages as given by Equations (3) and (4). This has led to the development of various algorithms that do not require estimating all possible models and instead approximate results (Madigan, et al. 1995, George and McCulloch 1993, Geweke 1999, Clyde, et al. 1996). In this study we adopt the 'stratified sampling'" method proposed by Sala-i-Martin, et al. (2004). Appendix I covers Bayesian Model Averaging, and Appendix II multiple imputation in the context of our model.

\section{Results}

Table 4 presents results for robust regressors from Bayesian model averaging over common factor (CF) models in panel A. For comparison, results from fixed-effect models (with both individual country effects and year effects) are presented in panel B. Results for posterior means and posterior standard deviations conditional on inclusion are as calculated by Equation (3) and (4) respectively. From the posterior density we estimate the posterior probability that a variable's coefficient has the same sign as its posterior mean conditional on inclusion, which is indicated as "Sign Certainty Probability". If sign certainty is above 95\%, then the coefficient would be 10-percent significant in a two-tail test in classical terms, and we can be $90 \%$ confident that the variable is a robust driver of HCE. We further report the fraction of specifications for which the absolute value of a determinant's t-statistic is larger than $2 .^{3}$ Estimates of the magnitude of impact of robust determinants on HCE growth are presented for the $\mathrm{CF}$ models. This shows the \% change in growth rate associated with a one within-country standard deviation (SD) \% change of the determinant. Results for determinants that are not robust are presented in figure $1{ }^{4}$ Sign certainty is plotted on the $\mathrm{x}$-axis, and in order to allow interpretation as 'Probability of determinant being positive', the values are subtracted from unity for determinants with a negative posterior mean. The fractions of significant specifications are plotted on the y-axis.

\footnotetext{
${ }^{2}$ For technical details, please refer to Sala-I-Martin et al. (2004) and its Technical Appendix.

${ }^{3}$ For ease of exposition referred to as 'significance' in the remainder of the paper.

${ }^{4}$ Tables of estimates are available from the corresponding author on request.
} 
We can identify 16 robust variables from the CF models. Growth in GDP is positively associated with expenditure growth, confirming results from many previous study that income is a critical factor in determining how much nations spend on medical care (Chernew and Newhouse, 2011). It consistently explains around $90 \%$ of variation in real health spending across countries and time (Smith et al., 2009). Empirical estimates tend to find a macro-level income elasticity of about 1.0 after adjusting for other factors that are correlated with GDP such as technology, medical prices and insurance, implying that health spending moves in tandem with GDP (Gerdtham and Jönsson, 2000). More recent studies estimate elasticities of below one, suggesting the necessity nature of healthcare (Dreger and Reimers, 2005, Baltagi and Moscone, 2010). This is confirmed by our results; a one SD \% increase in GDP growth rate is associated with a $.77 \%$ increase in HCE growth rate.

Growth in insurance premiums for private and social insurance is positively associated with growth in HCE; insurance payments make up part of measured healthcare expenditures, and growth in premiums are likely to directly translate into HCE growth. Impact is largest among all robust regressors at a $1.31 \%$ increase in HCE growth. However, changes in the proportion of health expenditures funded by social and private insurance are negatively associated with HCE growth; i.e. countries that have re-oriented their health system towards a greater role of social or private insurance in financing, and by default a smaller role for public financing, have experienced a reduction in HCE. According to our results, increases lead to $.96 \%$ and $.51 \%$ reductions in HCE, respectively. Woolhandler et al. (2003) have estimated that moving to a Canadian-style social insurance system would reduce U.S. administrative costs by 10-15 percent of total health spending, confirming our result. Research on the expenditures impact of private health insurance is conflicting, for a discussion in the context of OECD countries see Colombo and Tapay (2004). On the one hand, private insurers operating in a competitive market may improve efficiency in administering insurance plans and enforce pressures on health service providers to minimise costs. On the other hand, coverage provided by multiple competing insurers can be administratively costly, and market failures resulting from information asymmetries and moral hazard may ultimately increase costs. Our results for private insurance would support the first line of arguments.

An increase in pharmaceutical sales per capita is positively associated with healthcare expenditure growth. Pharmaceuticals account for almost a fifth of all health spending on average across OECD countries (Docteur et al., 2008), and diffusion of new drugs has been an important factor contributing to increased pharmaceutical expenditure and overall HCE 
(Docteur et al., 2008, Clemente et al., 2008). However, the relationship between pharmaceutical spending and total health spending is a complex one, in that increased expenditure on pharmaceuticals to tackle diseases may be offset by reduced morbidity and need for costly interventions in future (Dormont et al., 2006). This is not an effect we can analyse, and we find the impact of pharmaceuticals to be comparably high at $0.83 \%$ increase in $\mathrm{HCE}$ growth. An increase in the proportion of the population above 65 years is associated with an increase in HCE growth at $0.4 \%$. A straightforward explanation seems to be the greater morbidity among the elderly population, but some have contested this based on evidence that the impact of age disappears once proximity to death is controlled for (Zweifel et al., 2004). Healthcare resource use is most intense in the few months before death, and medical expenses during additional life years spent in relatively good health may hardly impact on overall lifetime spending. The unemployment rate is negatively associated with expenditure growth, i.e. an increase in the unemployment rate is associated with a decrease in HCEs. Unemployment rises in times of financial crises, and associated reductions in tax revenue and increases in the social budget devoted to unemployment benefits and other social contributions have been found to reduce public funds for healthcare (Cylus et al., 2012, de Belvis et al., 2012). Similarly, recessions slow the growth in wages with negative impact on private healthcare expenditures. Growth in public spending on education and expenditures of general government are positively associated with healthcare spending, indicating that spending across different public services is complementary rather than substitutive. Associations are $0.46 \%$ and $0.34 \%$, but the determinants are significant in only $88 \%$ and $53 \%$ of all specifications.

Inpatient care discharges and acute care beds are positively associated with HCE growth. Most countries have made efforts to substitute inpatient care with less costly outpatient and daycase treatments, and our result show that countries which were more successful with this substitution have indeed profited from a slower growth in HCE. Reductions are associated with $.35 \%$ and $.28 \%$ reductions in HCE (at low significance for beds, however). This result is confirmed by previous findings (Docteur and Oxley, 2003). An increase in the costs of expenditures on health administration is positively associated with expenditure growth although the effect is small at $0.35 \%$. In some countries, administration account for a sizable proportion of the health care budget. Highest costs are recorded for the USA, at around 31.0 percent of HCE in the United States. Rates are lower in most other countries, for example just under 17\% in Canada (Woolhandler et al., 2003). Our results confirm previous evidence (Hartwig and Sturm, 2014). Inpatient expenditures is negatively associated with HCE. This is 
a counterintuitive result that is difficult to explain, and also found by Hartwig and Sturm (2014), however, it is significant in less than $80 \%$ of specifications. Tobacco consumption has a robust positive association with HCE, but only $46 \%$ of specifications are significant.

A change towards, or away from, capitation remuneration and a public contract healthcare system are the only institutional determinants associated with a robust increase, or decrease, in HCE growth, however the effects are small at $0.22 \%$ and $0.05 \%$, and less than $90 \%$ of specifications are significant. Capitation is usually considered as cost-containing, which is not supported by our result. However, it has been found that there are great variations in the way capitation is implemented (Rice and Smith, 2001). Public contract systems are generally considered less successful in containing healthcare cost than public integrated systems, mainly because payment of providers is ex-post (Docteur and Oxley, 2003). This is confirmed by our finding. None of the other institutional variables are significant drivers of healthcare expenditures. This could be due to difficulties of measuring health system characteristics in binary variables, and also because there is relatively little change in such characteristics over time, and identification has mainly to rely on cross country variation.

There are a few determinants that nearly reach robustness and statistical significance (see figure 1). These are choice of hospital, GP or specialist, road traffic accidents and alcohol consumption, and at lower levels of significance, $R \& D$ expenditures and insurance coverage. Apart from those, sign certainty and fraction significant are low for the remaining determinants. Results from fixed effects and CF models are very similar, although four determinants are robust according to $\mathrm{CF}$ but not FE models, and one robust according to FE but not $\mathrm{CF}$ model.

\section{Conclusions}

Empirical models of healthcare expenditure growth are affected by at least three problems: unobserved heterogeneity in the effect of common shocks across countries, high model uncertainty, and missing data. These problems may lead to bias in the estimates of the impact of observable cost drivers, and could be partly responsible for the relative wide variations in results that have been found in the literature. Objective of our study is to address these problems by applying novel econometric methods that have been developed in the empirical economic growth literature. The innovative contributions of our study to the analysis of HCE growth are, first, to adopt panel data models with a multifactor error structure (Pesaran, 
2006, Bai, 2009) that allows for variations in the impact of common shocks on HCE growth across countries; second, to apply Bayesian model averaging methods (Koop et al., 2007) that address model uncertainty and identify important drivers of healthcare expenditure growth; third, to use multiple imputation techniques (Rubin, 1987) that incorporate the uncertainty surrounding the imputation into final model estimates. We compare our results with a standard fixed effects model of HCE growth, and find that estimates are very similar, at least for the most robust determinants. This lets us conclude that despite the supremacy of CF models on theoretical grounds, in practical application a standard FE model may be perfectly adequate. Our analysis has limitations. For many of our results it would be erroneous to infer a direct causal relation between a change in the determinant and impact on HCE growth. Some determinants may act as proxies for others that are not included in the models, or the relationship is highly complex and influenced by other factors. Our data is affected by unobserved variables and missing data. Although the OECD Health Statistics is the preferred dataset for analysis of HCE growth, some important drivers, in particular institutional variables, are poorly represented. Our results are based on historical trends over the past 32 years, and may not apply to the coming 32 years.

Despite the limitations, we can derive some conclusions. A greater reliance on private and social insurance, as opposed to public financing, seems to dampen growth. Competitive pressures in insurance markets seem to be associated with greater efficiency. Tackling the costs of pharmaceuticals, by regulation of the pharmaceuticals and devices markets, is another promising policy according to our results. Similarly, slimming health administration is predicted to curtail growth. Organisational reforms of the healthcare system should be directed to increase efficiency of the management of healthcare provision; further research is necessary to establish at what managerial level greatest efficiency gains can be expected. We further find that substitution of inpatient with outpatient care can reduce HCE growth, a policy that has been fostered by most countries in our study. Characteristics of the healthcare system and health indicators show weak associations with HCE growth, but it is important to keep in mind that these factors may still have an association with the level of expenditures. Overall, we hope that our results provide robust evidence to policy makers on the drivers that are most strongly associated with the growth in HCE, and will be used to inform effective policies in OECD countries. 
Table 1: List of OECD countries and years included in the study

\begin{tabular}{|c|c|}
\hline Country & Year \\
\hline Australia & $1981-2010$ \\
\hline Austria & $1981-2011$ \\
\hline Belgium & $1981-2011$ \\
\hline Canada & $1981-2012$ \\
\hline Chile & $1996-2012$ \\
\hline Czech Republic & 1991-2011 \\
\hline Denmark & 1981-2011 \\
\hline Estonia & $2000-2011$ \\
\hline Finland & $1981-2012$ \\
\hline France & 1991-2011 \\
\hline Germany & 1981-1990, 1993-2011 \\
\hline Greece & $1988-2011$ \\
\hline Hungary & $1992-2012$ \\
\hline Iceland & 1981-2012 \\
\hline Ireland & 1981-2011 \\
\hline Israel & $1981-2011$ \\
\hline Italy & 1989-2012 \\
\hline Japan & $1981-2010$ \\
\hline Korea & $1981-2012$ \\
\hline Luxembourg & 1996-2011 \\
\hline Mexico & $1991-2010$ \\
\hline Netherlands & $1981-2011$ \\
\hline New Zealand & 1981-2011 \\
\hline Norway & $1981-2012$ \\
\hline Poland & $1991-2011$ \\
\hline Portugal & $1981-2011$ \\
\hline Slovak Republic & $1998-2011$ \\
\hline Slovenia & 1996-2012 \\
\hline Spain & 1981-2011 \\
\hline Sweden & 1981-2011 \\
\hline Switzerland & 1981-2012 \\
\hline Turkey & $1981-2008$ \\
\hline United Kingdom & 1981-2011 \\
\hline United States & $1981-2011$ \\
\hline
\end{tabular}

Note: Country-years with missing values on healthcare expenditure growth are excluded from analysis. 
Table 2: Descriptive Statistics for the Original Data Set

\begin{tabular}{|c|c|c|c|c|c|c|}
\hline Variable & Description & Obs & Mean & Std. Dev. & Min & Max \\
\hline lnhce & Total expenditure on health (per capita, NCU at 2005 GDP price level) & 909 & 3.37 & 4.82 & -28.33 & 29.42 \\
\hline lnacc & Road traffic accidents (injured per million population) & 839 & -0.93 & 7.91 & -76.37 & 30.17 \\
\hline Inalc & Alcohol consumption (ltr per capita, ages $15+$ ) & 846 & -0.36 & 5.12 & -32.54 & 30.01 \\
\hline lnbsi & Acute care beds (per 1,000 population) & 628 & -1.63 & 3.70 & -29.09 & 34.80 \\
\hline pbirt & Births, live (per 1,000 population) & 889 & -0.11 & 0.42 & -3.10 & 3.70 \\
\hline pcanm & Neoplasms, deaths (per 100,000 population) & 831 & -1.39 & 5.36 & -26.20 & 27.90 \\
\hline pcove & Insurance coverage (\% of population) & 752 & 0.24 & 1.90 & -5.10 & 36.40 \\
\hline pfpr & Labor force participation rate, female (\% of female population ages $15+)$ & 552 & 450.90 & 89.18 & 100.87 & 666.70 \\
\hline lngdp & Gross domestic product (per capita, US\$ at 2005 PPP) & 909 & 4.83 & 3.53 & -10.37 & 19.38 \\
\hline lnger & R\&D expenditures (million of US\$ at 2005 PPP) & 592 & 5.04 & 7.39 & -35.35 & 49.68 \\
\hline pgp1 & Public coverage of health care (\% of total population) & 808 & 0.27 & 1.93 & -5.10 & 37.40 \\
\hline lngp & Generalist medical practitioners (per 1,000 population) & 457 & 0.01 & 0.06 & -0.53 & 0.55 \\
\hline pgsh & Expenditure of general government, total (\% of GDP) & 645 & 0.01 & 2.35 & -18.42 & 17.34 \\
\hline phemp & Health and social employment (\% total employment) & 495 & 0.12 & 0.47 & -2.51 & 5.49 \\
\hline lnhospc & General hospitals (per 1,000 population) & 525 & -1.74 & 5.37 & -39.01 & 36.85 \\
\hline lninp & Inpatient care discharges, all hospitals (per 100,000 population) & 610 & 0.43 & 3.43 & -27.66 & 16.55 \\
\hline lnlos & Length of stay in hospital, all causes (average days) & 504 & -1.64 & 4.74 & -33.85 & 21.67 \\
\hline Inmt & Life-years lost (all causes per 100,000 population, $0-69$ years) & 816 & -2.49 & 3.19 & -21.98 & 18.71 \\
\hline lnpha & Pharmaceutical sales (per capita, US\$ at 2005 PPP) & 456 & 5.60 & 6.59 & -22.99 & 32.99 \\
\hline Indoc & Physicians (per 1,000 population) & 579 & 1.97 & 6.06 & -34.79 & 65.68 \\
\hline Inins & Insurance premiums, private and social (per capita, US\$ at 2005 PPP) & 517 & 4.12 & 7.47 & -54.36 & 34.69 \\
\hline ppins & Private insurance expenditure (\% total health expenditure) & 577 & 0.07 & 0.57 & -7.76 & 3.17 \\
\hline ppop6 & Population above 65 years (\% total population) & 899 & 0.15 & 0.17 & -0.70 & 1.00 \\
\hline ppop8 & Population above 80 years ( $\%$ total population) & 876 & 0.07 & 0.08 & -0.50 & 0.40 \\
\hline ppuhe & Health expenditure, public (\% total health expenditure) & 762 & -0.03 & 2.04 & -16.10 & 15.10 \\
\hline pedx & Public spending on education, total (\% of government expenditure) & 515 & 0.04 & 0.71 & -4.61 & 3.43 \\
\hline psss & Social insurance expenditure (\% total health expenditure) & 626 & -0.04 & 1.86 & -23.10 & 10.72 \\
\hline lnta & Health administration, expenditures (per capita, NCU at 2005 GDP price level) & 477 & 4.25 & 22.27 & -150.41 & 248.49 \\
\hline ptexm & Inpatient expenditures (\% total health expenditure) & 594 & -0.41 & 2.44 & -22.00 & 9.70 \\
\hline lntob & Tobacco consumption (grams per capita, age $15+$ ) & 624 & -2.02 & 7.04 & -64.34 & 53.54 \\
\hline Indp & Population density (per km2) & 909 & 0.67 & 0.68 & -3.96 & 6.01 \\
\hline punem & Unemployment rate, total (\% civilian labour force) & 675 & 0.09 & 1.25 & -4.45 & 8.27 \\
\hline Inle & Life expectancy at age 65 (total) & 885 & 0.85 & 1.22 & -4.85 & 7.87 \\
\hline mic & Middle income country & 909 & 0.18 & 0.39 & 0.00 & 1.00 \\
\hline capit & Capitation remuneration (primary care) & 909 & 0.14 & 0.34 & 0.00 & 1.00 \\
\hline caseh & Fee-for-service (in-patient care) & 909 & 0.17 & 0.38 & 0.00 & 1.00 \\
\hline copay & Copayment for GP or hospital & 909 & 0.72 & 0.45 & 0.00 & 1.00 \\
\hline ffsa & Fee-for-service (primary care) & 909 & 0.29 & 0.46 & 0.00 & 1.00 \\
\hline free & Choice of hospital, GP or specialist & 909 & 0.97 & 0.18 & 0.00 & 1.00 \\
\hline gatek & Gatekeeper GPs & 909 & 0.52 & 0.50 & 0.00 & 1.00 \\
\hline globu & Global Budgets (in-patient care) & 909 & 0.33 & 0.47 & 0.00 & 1.00 \\
\hline hespc & Public contract healthcare system & 909 & 0.53 & 0.50 & 0.00 & 1.00 \\
\hline mixgp & Mix of capitation and fee-for-service (primary care) & 909 & 0.30 & 0.46 & 0.00 & 1.00 \\
\hline - & Salary renumeration (primary & 909 & 0.20 & 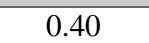 & 0.00 & 1.00 \\
\hline
\end{tabular}

Notes: Summary statistics are calculated across countries and years; level variables are converted into growth rates and prefixed "ln"; proportion/share variables are first differenced and prefixed "p". 
Table 3.Descriptive Statistics for Two Imputed Data Sets

\begin{tabular}{|c|c|c|c|c|c|c|c|c|}
\hline \multirow[b]{2}{*}{ Variable } & \multicolumn{4}{|c|}{ 1st Imputed data set } & \multicolumn{4}{|c|}{ 50th Imputed data set } \\
\hline & Mean & Std. Dev. & Min & $\operatorname{Max}$ & Mean & Std. Dev. & Min & $\operatorname{Max}$ \\
\hline Inacc & -1.26 & 9.02 & -76.37 & 30.17 & -1.00 & 8.65 & -76.37 & 30.17 \\
\hline Inalc & -0.37 & 5.05 & -32.54 & 30.01 & -0.34 & 5.10 & -32.54 & 30.01 \\
\hline Inbsi & -1.32 & 4.05 & -29.09 & 34.80 & -1.33 & 4.51 & -29.09 & 34.80 \\
\hline pbirt & -0.12 & 0.42 & -3.10 & 3.70 & -0.11 & 0.43 & -3.10 & 3.70 \\
\hline pcanm & -1.15 & 5.93 & -26.20 & 27.90 & -1.31 & 5.38 & -26.20 & 27.90 \\
\hline pcove & 0.25 & 1.82 & -5.10 & 36.40 & 0.27 & 1.91 & -5.10 & 36.40 \\
\hline pfpr & 454.78 & 92.36 & 100.87 & 666.70 & 454.41 & 89.99 & 100.87 & 666.70 \\
\hline Ingdp & 4.83 & 3.53 & -10.37 & 19.38 & 4.83 & 3.53 & -10.37 & 19.38 \\
\hline lnger & 6.03 & 8.50 & -35.35 & 49.68 & 4.99 & 8.98 & -35.35 & 49.68 \\
\hline pgp1 & 0.32 & 1.92 & -5.10 & 37.40 & 0.32 & 1.95 & -5.10 & 37.40 \\
\hline lngp & 0.02 & 0.08 & -0.53 & 0.55 & 0.01 & 0.08 & -0.53 & 0.55 \\
\hline pgsh & -0.03 & 3.12 & -18.42 & 17.34 & -0.09 & 2.72 & -18.42 & 17.34 \\
\hline phemp & 0.15 & 0.60 & -2.51 & 5.49 & 0.14 & 0.58 & -2.51 & 5.49 \\
\hline Inhospc & -2.27 & 6.58 & -39.01 & 36.85 & -1.73 & 5.53 & -39.01 & 36.85 \\
\hline Ininp & 0.40 & 3.67 & -27.66 & 16.55 & 0.92 & 4.69 & -27.66 & 16.55 \\
\hline Inlos & -2.52 & 5.06 & -33.85 & 21.67 & -2.23 & 5.24 & -33.85 & 21.67 \\
\hline Inmt & -2.44 & 3.24 & -21.98 & 18.71 & -2.47 & 3.22 & -21.98 & 18.71 \\
\hline Inpha & 7.00 & 7.62 & -22.99 & 32.99 & 6.72 & 6.59 & -22.99 & 32.99 \\
\hline Indoc & 1.77 & 6.80 & -34.79 & 65.68 & 1.91 & 6.34 & -34.79 & 65.68 \\
\hline Inins & 4.41 & 9.65 & -54.36 & 34.69 & 4.16 & 8.75 & -54.36 & 34.69 \\
\hline ppins & 0.05 & 0.64 & -7.76 & 3.17 & 0.07 & 0.61 & -7.76 & 3.17 \\
\hline ppop6 & 0.15 & 0.17 & -0.70 & 1.00 & 0.15 & 0.17 & -0.70 & 1.00 \\
\hline ppop8 & 0.07 & 0.08 & -0.50 & 0.40 & 0.07 & 0.08 & -0.50 & 0.40 \\
\hline ppuhe & -0.04 & 1.96 & -16.10 & 15.10 & 0.01 & 2.02 & -16.10 & 15.10 \\
\hline pedx & 0.08 & 0.81 & -4.61 & 3.43 & 0.08 & 0.86 & -4.61 & 3.43 \\
\hline psss & -0.05 & 2.17 & -23.10 & 10.72 & -0.10 & 1.97 & -23.10 & 10.72 \\
\hline Inta & -0.61 & 32.85 & -150.41 & 248.49 & 0.64 & 31.03 & -150.41 & 248.49 \\
\hline ptexm & -0.51 & 2.92 & -22.00 & 9.70 & -0.25 & 2.83 & -22.00 & 9.70 \\
\hline Intob & 0.55 & 11.58 & -64.34 & 53.54 & -2.71 & 7.35 & -64.34 & 53.54 \\
\hline Indp & 0.67 & 0.68 & -3.96 & 6.01 & 0.67 & 0.68 & -3.96 & 6.01 \\
\hline punem & 0.04 & 1.22 & -4.45 & 8.27 & 0.14 & 1.23 & -4.45 & 8.27 \\
\hline Inle & 0.83 & 1.31 & -9.33 & 7.87 & 0.82 & 1.30 & -6.57 & 7.87 \\
\hline
\end{tabular}


Table 4. Bayesian Model Averaging Estimation Results for Robust Determinants of Healthcare Expenditure Growth

\begin{tabular}{|c|c|c|c|c|c|c|c|c|c|c|}
\hline \multirow[b]{2}{*}{ Determinant } & & \multicolumn{5}{|c|}{ A. Common factor models } & \multicolumn{4}{|c|}{ B. Fixed effect models } \\
\hline & & $\begin{array}{l}\text { Impact on } \\
\text { HCE growth } \\
\text { (SD change) }\end{array}$ & $\begin{array}{l}\text { Posterior } \\
\text { Mean }\end{array}$ & $\begin{array}{l}\text { Posterior } \\
\text { Standard } \\
\text { Deviation }\end{array}$ & $\begin{array}{c}\text { Sign } \\
\text { Certainty } \\
\text { Probability }^{2}\end{array}$ & $\begin{array}{c}\text { Fraction of } \\
\text { Regressions } \\
\text { with |tstat|>2 }\end{array}$ & $\begin{array}{l}\text { Posterior } \\
\text { Mean }\end{array}$ & $\begin{array}{l}\text { Posterior } \\
\text { Standard } \\
\text { Deviation }\end{array}$ & $\begin{array}{c}\text { Sign } \\
\text { Certainty } \\
\text { Probability }\end{array}$ & $\begin{array}{c}\text { Fraction of } \\
\text { Regressions } \\
\text { with } \\
\mid \text { tstat } \mid>2\end{array}$ \\
\hline $\begin{array}{l}\text { Insurance premiums, private and social (per } \\
\text { capita, US\$ at } 2005 \text { PPP) }\end{array}$ & $\operatorname{lnins}$ & 1.31 & $0.2220 * * * 3$ & 0.0556 & 1 & 1 & $0.2143 * * *$ & 0.057 & 1 & 1 \\
\hline $\begin{array}{l}\text { Social insurance expenditure (\% total health } \\
\text { expenditure) }\end{array}$ & psss & -0.96 & $-0.8086^{* * *}$ & 0.1746 & 1 & 1 & $-0.8320 * * *$ & 0.1793 & 1 & 1 \\
\hline $\begin{array}{l}\text { Pharmaceutical sales (per capita, US\$ at } 2005 \\
\text { PPP) }\end{array}$ & lnpha & 0.83 & $0.1537 * * *$ & 0.0408 & 0.9997 & 0.9987 & $0.1449 * * *$ & 0.0413 & 0.9993 & 0.9958 \\
\hline $\begin{array}{l}\text { Unemployment rate, total (\% civilian labour } \\
\text { force) }\end{array}$ & punem & -0.81 & $-0.7289 * * *$ & 0.1779 & 0.9998 & 0.9995 & $-0.7932 * * *$ & 0.2 & 0.9998 & 1 \\
\hline $\begin{array}{l}\text { Gross domestic product (per capita, US\$ at } \\
2005 \text { PPP) }\end{array}$ & lngdp & 0.77 & $0.2329 * * *$ & 0.0814 & 0.9955 & 0.971 & $0.2589 * * *$ & 0.0794 & 0.9978 & 0.9767 \\
\hline $\begin{array}{l}\text { Private insurance expenditure (\% total health } \\
\text { expenditure) }\end{array}$ & ppins & -0.51 & $-1.3837 * * *$ & 0.6674 & 0.9982 & 0.9987 & $-1.3412 * * *$ & 0.6805 & 0.9971 & 0.9998 \\
\hline $\begin{array}{l}\text { Public spending on education, total ( } \% \text { of } \\
\text { government expenditure) }\end{array}$ & pedx & 0.46 & $0.7309 * *$ & 0.3136 & 0.9883 & 0.8765 & $0.7337 * *$ & 0.3545 & 0.9782 & 0.7834 \\
\hline $\begin{array}{l}\text { Population above } 65 \text { years ( } \% \text { total } \\
\text { population) }\end{array}$ & ppop6 & 0.40 & $3.0026 * *$ & 1.1341 & 0.9932 & 0.9413 & $2.4764 *$ & 1.229 & 0.9746 & 0.6468 \\
\hline $\begin{array}{l}\text { Health administration, expenditures (per } \\
\text { capita, NCU at } 2005 \text { GDP price level) }\end{array}$ & lnta & 0.35 & $0.0196^{* * *}$ & 0.0071 & 0.9953 & 0.9884 & $0.0201 * *$ & 0.0085 & 0.9888 & 0.9779 \\
\hline $\begin{array}{l}\text { Inpatient care discharges, all hospitals (per } \\
100,000 \text { population) }\end{array}$ & $\operatorname{lninp}$ & 0.35 & $0.1324 * *$ & 0.0566 & 0.9891 & 0.9202 & $0.1481 * *$ & 0.0656 & 0.9858 & 0.9151 \\
\hline $\begin{array}{l}\text { Expenditure of general government, total (\% } \\
\text { of GDP) }\end{array}$ & pgsh & 0.34 & $0.1626^{*}$ & 0.0916 & 0.9658 & 0.5331 & $0.2032 *$ & 0.1068 & 0.9724 & 0.4769 \\
\hline $\begin{array}{l}\text { Inpatient expenditures (\% total health } \\
\text { expenditure) }\end{array}$ & ptexm & -0.34 & $-0.1617 *$ & 0.0802 & 0.9719 & 0.7905 & - & - & - & - \\
\hline Acute care beds (per 1,000 population) & lnbsi & 0.28 & $0.0954^{*}$ & 0.0507 & 0.9659 & 0.5511 & $0.1318 * *$ & 0.0634 & 0.9779 & 0.7393 \\
\hline $\begin{array}{l}\text { Tobacco consumption (grams per capita, age } \\
15+\text { ) }\end{array}$ & lntob & 0.25 & $0.0408 *$ & 0.0225 & 0.9619 & 0.4578 & - & - & - & - \\
\hline Capitation remuneration (primary care) & capit & 0.22 & $1.9228^{*}$ & 1.0495 & 0.97 & 0.872 & - & - & - & - \\
\hline Public contract healthcare system & hespc & 0.05 & $2.2973 * *$ & 1.0279 & 0.9815 & 0.8957 & - & - & - & - \\
\hline Salary remuneration (primary care) & ws & - & - & - & - & - & $-1.9581 *$ & 1.0934 & 0.9601 & 0.5446 \\
\hline
\end{tabular}


Figure 1: Non-robust Determinants of Healthcare Expenditure Growth

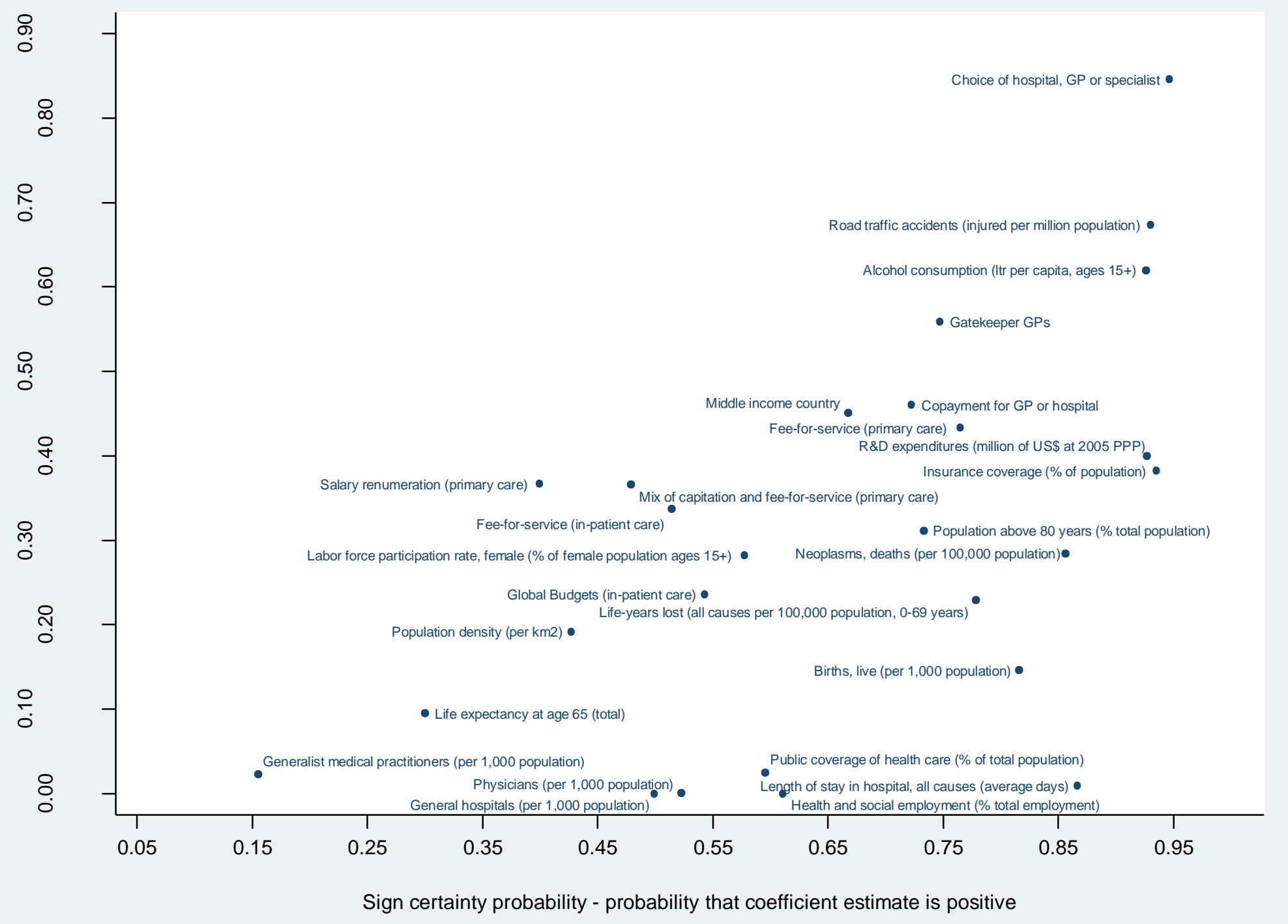

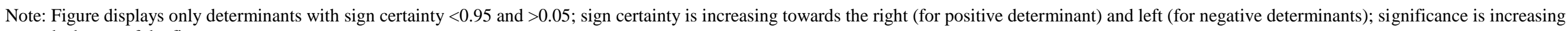
towards the top of the figure. 


\section{Appendix I Bayesian Model Averaging}

Most studies that use Bayesian Model Averaging (BMA) to identify determinants of economic growth at country level are based on cross-sectional models. ${ }^{5}$ Let $\boldsymbol{y}=\boldsymbol{X} \boldsymbol{\beta}+\boldsymbol{\varepsilon}$ represent a generic regression model of health care expenditure growth $(\boldsymbol{y})$ on a set of growth determinants $(\boldsymbol{X})$. Given the large number of potential growth determinants, there potentially exist an enormous amount of empirical models when the empirical researcher seeks to explore different combination of determinants. Suppose we have $K$ potential determinants, we then would have a maximum of $2^{K}$ possible combinations of regressors, i.e. $2^{K}$ different models to estimate. Let $M_{r}\left(r=1,2, \ldots, 2^{K}\right)$ denote the $r$ th model under consideration, then $M_{r}$ depends on a set of growth determinants, $\boldsymbol{X}^{r}$, and their corresponding coefficients $\boldsymbol{\beta}^{r}$. By Bayes' rule in densities, the posterior density for $\beta^{r}$ under model $M_{r}$ is written as

$$
p\left(\boldsymbol{\beta}^{r} \mid \boldsymbol{y}, M_{r}\right)=\frac{f\left(\boldsymbol{y} \mid \boldsymbol{\beta}^{r}, M_{r}\right) p\left(\boldsymbol{\beta}^{r} \mid M_{r}\right)}{f\left(\boldsymbol{y} \mid M_{r}\right)},
$$

where $p\left(\boldsymbol{\beta}^{r} \mid M_{r}\right)$ is the prior density of $\boldsymbol{\beta}^{r} ; f\left(\boldsymbol{y} \mid \boldsymbol{\beta}^{r}, M_{r}\right)$ denotes likelihood of $\boldsymbol{y}$ given $\boldsymbol{\beta}^{r}$ under model $M_{r}$; and $f\left(\boldsymbol{y} \mid M_{r}\right)$ is the prior density of $\boldsymbol{y}$.

Using Bayes' rule, the posterior probability, $p\left(M_{r} \mid \boldsymbol{y}\right)$ for $r=1,2, \ldots, 2^{K}$, can be obtained as

$$
p\left(M_{r} \mid \boldsymbol{y}\right)=\frac{f\left(\boldsymbol{y} \mid M_{r}\right) p\left(M_{r}\right)}{f(\boldsymbol{y})}
$$

which can be used to assess the degree of support for $M_{r}$. The prior density of $M_{r}$, i.e. $p\left(M_{r}\right)$, measures how likely we believe $M_{r}$ to be the correct model concerning the relative likelihood of all possible models before considering the data. $f\left(\boldsymbol{y} \mid M_{r}\right)$ is the marginal likelihood and is calculated by integrating both sides of Equation (A-1) with respect to $\boldsymbol{\beta}^{r}$. Use the fact that $\int p\left(\boldsymbol{\beta}^{r} \mid \boldsymbol{y}, M_{r}\right) d \boldsymbol{\beta}^{r}=1$, we get

$$
f\left(\boldsymbol{y} \mid M_{r}\right)=\int f\left(\boldsymbol{y} \mid \boldsymbol{\beta}^{r}, M_{r}\right) p\left(\boldsymbol{\beta}^{r} \mid M_{r}\right) d \boldsymbol{\beta}^{r}
$$

Let $\boldsymbol{\beta}$ be a vector of parameters that has a common interpretation in all models, i.e. $\boldsymbol{\beta}$ is function of $\beta^{r}$ for each $r=1,2, \ldots, 2^{K}$. According to the rules of probabilities, we can calculate the posterior density of the parameters for all the models under consideration as

5 To the best knowledge of authors, the only one exception is Moral-Benito MORAL-BENITO, E. 2012. Determinants of economic growth: a Bayesian panel data approach. Review of Economics and Statistics, 94, 566-579.. 


$$
p(\boldsymbol{\beta} \mid \boldsymbol{y})=\sum_{r=1}^{2^{K}} p\left(M_{r} \mid \boldsymbol{y}\right) p\left(\boldsymbol{\beta} \mid \boldsymbol{y}, M_{r}\right) .
$$

Follow Raftery (1995) and Sala-i-Martin et al. (2004), the posterior probability of model $M_{r}$ is

$$
p\left(M_{r} \mid \boldsymbol{y}\right)=\frac{p\left(M_{r}\right)(N T)^{-k^{r} / 2} S S E_{r}^{-N T / 2}}{\sum_{j=1}^{2^{K}} p\left(M_{j}\right)(N T)^{-k^{j} / 2} S S E_{j}^{-N T / 2}}
$$

where $N T$ is the number of observations, $k^{r}$ is the number of regressors included in model $M_{r}$, and $S S E_{r}$ is the sum of squared residuals from the $r$ th regression model of $M_{r}$.

Regarding the specification of prior probabilities attached to different models, $p\left(M_{r}\right)$, a common practice is to assign equal prior probability to each model. This however has troubling implications when the number of models under consideration is large. In particular it implies a very strong prior belief that the number of regressors included in the true model is very large, with expected model size equal to $K / 2$. Instead of choosing prior probabilities for different models, we specify a prior mean model size, $\bar{k}$. Each variable has the same prior probability, i.e. $\bar{k} / K$, of being included, and the probability is independent of the inclusion of any other variables. In our empirical analysis, we choose $\bar{k}=7$ but also compare results to $\bar{k}=5^{6}$. We find that different prior assumptions about the model size have no practical impact on the results.

6 Results are available upon request. 


\section{Appendix II Multiple Imputation}

For each imputed data-set, we estimate the common factor model in different specifications. Let $\hat{\boldsymbol{\beta}}_{m}^{r}$ represent the estimated parameters from common factor model with specification $M_{r}\left(r=1,2, \ldots, 2^{K}\right)$ by using the $m$-th $(m=1,2, \ldots, M)$ imputed data set. Let $\left\{\left(\hat{\boldsymbol{\beta}}_{m}^{r}, \hat{\boldsymbol{U}}_{m}^{r}\right): m=1,2, \ldots, M\right\}$ be the completed-data point estimates and variance-covariance estimates of $\boldsymbol{\beta}^{r}$ from $M$ imputed datasets. For $M_{r}$, the MI point estimation of $\boldsymbol{\beta}^{r}$ is given as

$$
\hat{\boldsymbol{\beta}}^{r}=\frac{1}{M} \sum_{m=1}^{M} \hat{\boldsymbol{\beta}}_{m}^{r}
$$

and the MI variance-covariance estimate is

$$
\operatorname{Var}\left(\hat{\boldsymbol{\beta}}^{r}\right)=M^{-1} \sum_{m=1}^{M} \hat{\mathbf{U}}_{m}^{r}+\left(1+M^{-1}\right) \sum_{m=1}^{M}\left(\hat{\boldsymbol{\beta}}_{m}^{r}-\hat{\boldsymbol{\beta}}^{r}\right)\left(\hat{\boldsymbol{\beta}}_{m}^{r}-\hat{\boldsymbol{\beta}}^{r}\right)^{\prime} /(M-1) .
$$




\section{References}

ANDREWS, D. W. 2005. Cross-section Regression with Common Shocks. Econometrica, 73, 1551-1585.

BAI, J. 2009. Panel data models with interactive fixed effects. Econometrica, 77, 1229-1279.

BAKER, L. C. \& WHEELER, S. K. 1998. Managed care and technology diffusion: the case of MRI. Health Affairs, 17, 195207.

BALTAGI, B. H. \& MOSCONE, F. 2010. Health care expenditure and income in the OECD reconsidered: Evidence from panel data. Economic Modelling, 27, 804-811.

CASE, A. C. 1991. Spatial patterns in household demand. Econometrica, 59, 953-965.

CHERNEW, M. E. \& NEWHOUSE, J. P. 2011. Chapter One - Health Care Spending Growth. In: MARK V. PAULY, T. G. M. \& PEDRO, P. B. (eds.) Handbook of Health Economics. Elsevier.

CHRISTIANSEN, T., BECH, M., LAURIDSEN, J. \& NIELSEN, P. 2006. Demographic changes and aggregate health-care expenditure in Europe. . In: EICHER, T. S. (ed.) ENEPRI Research Reports. European Network of Economic Policy Research Institutes.

CLEMENTE, J., MARCUELLO, C. \& MONTAÑÉS, A. 2008. Pharmaceutical expenditure, total health-care expenditure and GDP. Health Economics, 17, 1187-1206.

COAKLEY, J., FUERTES, A.-M. \& SMITH, R. 2006. Unobserved heterogeneity in panel time series models. Computational Statistics \& Data Analysis, 50, 2361-2380.

COLOMBO, F. \& TAPAY, N. 2004. Private health insurance in OECD countries: The Benefits and Costs for Individuals and Health Systems. In: OECD PUBLISHING (ed.) OECD Health Working Papers.

CONLEY, T. G. 1999. GMM estimation with cross sectional dependence. Journal of Econometrics, 92, 1-45.

CYLUS, J., MLADOVSKY, P. \& MCKEE, M. 2012. Is There a Statistical Relationship between Economic Crises and Changes in Government Health Expenditure Growth? An Analysis of Twenty-Four European Countries. Health Services Research, 47, 2204-2224.

DE BELVIS, A. G., FERRÈ, F., SPECCHIA, M. L., VALERIO, L., FATTORE, G. \& RICCIARDI, W. 2012. The financial crisis in Italy: Implications for the healthcare sector. Health Policy, 106, 10-16.

DI MATTEO, L. \& DI MATTEO, R. 1998. Evidence on the determinants of Canadian provincial government health expenditures: 1965-1991. Journal of Health Economics, 17, 211-228.

DOCTEUR, E. \& OXLEY, H. 2003. Health-care systems: lessons from the reform experience. In: OECD PUBLISHING (ed.) OECD Health Working Papers Paris.

DOCTEUR, E., PARIS, V. \& MOISE, P. 2008. Pharmaceutical pricing policies in a global market. In: OECD PUBLISHING (ed.) OECD Health Policy Studies. Paris: OECD.

DORMONT, B., GRIGNON, M. \& HUBER, H. 2006. Health expenditure growth: reassessing the threat of ageing. Health Economics, 15, 947-963.

DREGER, C. \& REIMERS, H.-E. 2005. Health care expenditures in OECD countries: a panel unit root and cointegration analysis. In: INSTITUTE FOR THE STUDY OF LABOUR (ed.) IZA Discussion Paper. Wismar: IZA Discussion paper series.

GERDTHAM, U.-G. \& JÖNSSON, B. 2000. Chapter 1 International comparisons of health expenditure: Theory, data and econometric analysis. In: ANTHONY, J. C. \& JOSEPH, P. N. (eds.) Handbook of Health Economics. Elsevier.

GERDTHAM, U.-G. \& LÖTHGREN, M. 2000. On stationarity and cointegration of international health expenditure and GDP. Journal of Health Economics, 19, 461-475.

GREENHALGH, T., ROBERT, G., BATE, P., MACFARLANE, F. \& KYRIAKIDOU, O. 2008. Diffusion of innovations in health service organisations: a systematic literature review, Blackwell Publishing.

HARTWIG, J. 2008. What drives health care expenditure?-Baumol's model of 'unbalanced growth' revisited. Journal of Health Economics, 27, 603-623.

HARTWIG, J. \& STURM, J.-E. 2014. Robust determinants of health care expenditure growth. Applied Economics, 46, 4455-4474.

HASHIMOTO, H., NOGUCHI, H., HEIDENREICH, P., SAYNINA, O., MORELAND, A., MIYAZAKI, S., IKEDA, S., KANEKO, Y. \& IKEGAMI, N. 2006. The diffusion of medical technology, local conditions, and technology re-invention: $A$ comparative case study on coronary stenting. Health Policy, 79, 221-230.

HORTON, N. J. \& LIPSITZ, S. R. 2001. Multiple Imputation in Practice. The American Statistician, 55, 244-254.

HUANG, X. 2012. Nonparametric Estimation in Large Panels with Cross-Sectional Dependence. Econometric Reviews, 32, 754-777.

KENWARD, M. G. \& CARPENTER, J. 2007. Multiple imputation: current perspectives. Statistical Methods in Medical Research, 16, 199-218.

KOOP, G., POIRIER, D. J. \& TOBIAS, J. L. 2007. Bayesian econometric methods, Cambridge University Press. 
LEAMER, E. E. 1978. Specification searches. New York: Wiley.

LYTTKENS, C. H. 2001. Technological change around the world: evidence from heart attack care. Health Affairs, 20, 2542.

MCCLELLAN, M. \& KESSLER, D. 1999. A Global Analysis Of Technological Change In Health Care: The Case Of Heart Attacks. Health Affairs, 18, 250-255.

MELLO-SAMPAYO, D. \& DE SOUSA-VALE, S. 2014. Financing Health Care Expenditure in the OECD Countries: Evidence from a Heterogeneous, Cross-Sectional Dependent Panel. Panoeconomicus, 2, 207-225.

MORAL-BENITO, E. 2010. Model averaging in economics. In: MUNICH PERSONAL REPEC ARCHIVE (ed.). Munich, Germany.

MORAL-BENITO, E. 2012. Determinants of economic growth: a Bayesian panel data approach. Review of Economics and Statistics, 94, 566-579.

OECD 2014. OECD Health Statistics. In: OECD (ed.). Paris: OECD.

OKUNADE, A. A. \& MURTHY, V. N. 2002. Technology as a 'major driver' of health care costs: a cointegration analysis of the Newhouse conjecture. Journal of Health Economics, 21, 147-159.

PACKER, C., SIMPSON, S. \& STEVENS, A. 2006. International diffusion of new health technologies: A ten-country analysis of six health technologies. International Journal of Technology Assessment in Health Care, 22, 419428.

PENG, B. \& FORCHINI, G. 2014. Consistent Estimation of Panel Data Models with a Multifactor Error Structure when the Cross Section Dimension is Large. In: ECONOMICS DISCIPLINE GROUP (ed.) Working Paper. Sydney, Australia: University of Technology Sydney.

PESARAN, M. H. 2006. Estimation and inference in large heterogeneous panels with a multifactor error structure. Econometrica, 74, 967-1012.

RAFTERY, A. E. 1995. Bayesian model selection in social research. Sociological methodology, 25, 111-164.

RICE, N. \& SMITH, P. C. 2001. Capitation and Risk Adjustment in Health Care Financing: An International Progress Report. Milbank Quarterly, 79, 81-113.

RUBIN, D. B. 1987. Multiple Imputation for Nonresponse in Surveys (Wiley Series in Probability and Statistics).

SALA-I-MARTIN, X., DOPPELHOFER, G. \& MILLER, R. I. 2004. Determinants of Long-Term Growth: A Bayesian Averaging of Classical Estimates (BACE) Approach. American Economic Review, 94, 813-835.

SMITH, S., NEWHOUSE, J. P. \& FREELAND, M. S. 2009. Income, Insurance, And Technology: Why Does Health Spending Outpace Economic Growth? Health Affairs, 28, 1276-1284.

SOLOW, R. M. 1957. Technical change and the aggregate production function. The Review of Economics and Statistics, 39, 312-320.

STATA 2013. Multiple Imputation Reference Manual, College Station, Texas, STATA Press.

SU, L. \& JIN, S. 2012. Sieve estimation of panel data models with cross section dependence. Journal of Econometrics, 169, 34-47.

WEIL, T. P. 1994. Comparisons of medical technology in Canadian, German, and US Hospitals. Hospital \& Health Services Administration, 40, 524-533.

WHITE, I. R., ROYSTON, P. \& WOOD, A. M. 2011. Multiple imputation using chained equations: issues and guidance for practice. Statistics in Medicine, 30, 377-399.

WOOLHANDLER, S., CAMPBELL, T. \& HIMMELSTEIN, D. U. 2003. Costs of health care administration in the United States and Canada. New England Journal of Medicine, 349, 768-775.

ZWEIFEL, P., FELDER, S. \& WERBLOW, A. 2004. Population Ageing and Health Care Expenditure: New Evidence on the" Red Herring". Geneva Papers on Risk and Insurance. Issues and Practice. 